\title{
LA ORALIDAD Y LA PROBLEMÁTICA PARA SU IMPLEMENTACIÓN EN EL PROCESO CIVIL. BAJO UNA MIRADA A NUESTRO ORIGINARIO CPC DE 1993
}

\section{ORALITY AND THE PROBLEM FOR ITS IMPLEMENTATION IN THE CIVIL PROCESS. UNDER A LOOK AT OUR ORIGINAL 1993 CPC}

Alexander Rioja Bermúdez

* Docente universitario en Derecho Procesal Civil, conferencista, autor de diversas obras en Derecho Procesal.

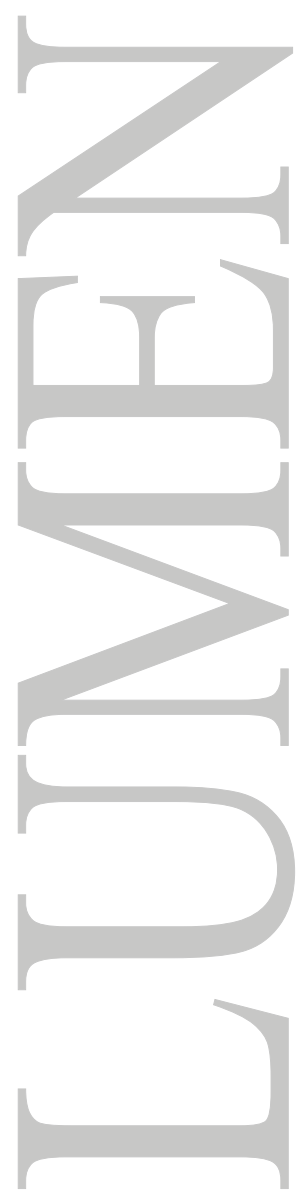




\title{
LA ORALIDAD Y LA PROBLEMÁTICA PARA SU IMPLEMENTACIÓN EN EL PROCESO CIVIL. BAJO UNA MIRADA A NUESTRO ORIGINARIO CPC DE 1993
}

\author{
ORALITY AND THE PROBLEM FOR ITS IMPLEMENTATION IN THE CIVIL \\ PROCESS. UNDER A LOOK AT OUR ORIGINAL 1993 CPC
}

Alexander Rioja Bermúdez

\begin{abstract}
RESUMEN
La presente es un trabajo que busca poner de manifiesto los problemas que aparecieron con la puesta en aplicación del Código Procesal Civil de 1993 los cuales deben ser tomados en cuenta en esta segunda etapa de la oralidad del proceso civil y evitar volver a cometer los mismos errores, permitiendo que sea más sólida y más efectiva la implementación del sistema oral en nuestra realidad jurídica.
\end{abstract}

\section{PALABRAS CLAVE}

Oralidad, antecedentes de oralidad, principios oralidad, Juez, inmediación, Concentración, Publicidad, Etapas del proceso.

\section{ABSTRACT}

The present is a work that seeks to highlight the problems that appeared with the implementation of the Civil Procedure Code of 1993 which must be taken into account in this second stage of the orality of the civil process and avoid making the same mistakes again, allowing the implementation of the oral system in our legal reality to be more robust and more effective.

\section{KEY WORDS}

Orality, orality history, orality principles, Judge, immediacy, Concentration, Advertising, Process stages,

\section{INTRODUCCIÓN}

Si bien en nuestro sistema procesal civil actual, la oralidad se encuentra en una etapa de implementación, poniéndose de manifiesto la idea de sus ventajas y como esta podría significar un cambio importante para el proceso civil nacional, existen quienes más allá de sus bondades señalan la existencia de problemas aun no resueltos en lugares donde ya se implementó este sistema. Pero, creemos que más allá de conocer estas vicisitudes lo importante es saber de ellas lo que nos permitirá evitar caer en dichos errores.

En este aspecto y analizando nuestra reciente realidad histórica con la puesta en vigencia del Código Procesal Civil de 1993 (la oralidad en el proceso civil), es posible poner de manifiesto algunos inconvenientes que pudieran nuevamente aparecer en esta segunda fase de la oralidad. De esta manera la idea es advertir que se repitan situaciones que marcaron una disconformidad con esta norma procesal e impidieron su pleno aplicación en nuestra realidad y llevaron a modificarlo de tal forma que perdió la esencia plena de la oralidad que se quería implementar.

La idea de la implementación de la oralidad tiene por objeto atacar un sistema ya desfasado que a la postre ha venido a poner de manifiesto un servicio de justicia acabado, lento, desastroso, inerte a los cambios, a las necesidades y requerimientos actuales; así como también advertir la introducción 
de cambios legislativos sin un análisis profundo de la realidad vigente importando modelos que no han sido la solución.

El sistema escritural con más de 400 años de vigencia no ha sido el método que ha permitido tener una justicia oportuna pronta ni eficaz, ha pasado por muchos cambios, pero estos no han pasado por sus operadores, ni tampoco dichos cambios han sido producto de las necesidades propias de nuestra sociedad.

Si bien se ha pintado a la oralidad como la panacea en la solución para mejorar nuestro sistema de justicia, hay que tomar con pinzas estas afirmaciones, por lo que bajo las condiciones vigentes es también poco probable que "sea" la solución a nuestra realidad. En la búsqueda de la respuesta al sistema judicial vigente las miradas se han centrado en este sistema, sin embargo, se debe precisar que éste no es propiamente uno nuevo y que tanto Klein como Capeletti mostraban su predilección, allá a inicios de 1950.

Contrariamente, algunos autores han destacado todos los defectos y las deficiencias del sistema escritural dedicándose a señalar los aspectos negativos y muy pocos casos los aspectos positivos del sistema vigente. Así, cuando se hace referencia al sistema escritural, se concluye que este "ya no da para más". En tal sentido Jordi señala que "Todo ello, en el fondo, no es más que una lógica reacción doctrinal contra tantos siglos de procedimiento escrito, reacción que en algunos momentos ha sido incluso visceral." (NIEVA FENOLL, 2020)

Ante esta circunstancia se ha centrado la mirada en la oralidad tratando de resaltar aquellos aspectos positivos con la finalidad de mostrar y precondicionar su necesidad de puesta en vigencia a toda costa y que por el solo hecho de argumentar los principios que la respaldan (publicidad, concentración e inmediación) permite su viabilidad y por ende su éxito para la aplicación de una justicia más moderna.

No se ha percatado ni aprendido de la experiencia de nuestro originario Código Procesal Civil de 1993, un código plasmado de oralidad, en la que se fijaron aquellos principios que sustentaban este sistema; sin embargo no fueron tomados en cuenta, dejándose de lado la participación y labor del juez como director del proceso, la falta de una comprensión por parte de los abogados como principales actores del proceso, la dilación innecesaria de los procesos y de las actuaciones procesales, la falta de la aplicación de las medidas disciplinarias por parte del juez, marcaron actitudes que desdecían la oralidad del proceso civil.

Asimismo, el hecho de no dejar de depender del sistema escritural en su totalidad, la falta de celeridad de los procesos aun cuando había los mecanismos para poder atacarla y evitarla, la ausencia de atención e interés por los propios jueces que no se encontraban capacitados para utilizar esta herramienta y poder lograr una justicia verdaderamente más adecuada a esa realidad, resultaron ser circunstancias que mermaron la aplicación del CPC de 1993.

De tal forma, que el principio de inmediación nunca se plasmó, pues las audiencias se realizaban muchas veces a puerta cerrada y las partes únicamente cumplían con la formalidad de asistir para firmar un acta en las que no participaron activamente o en la que, en el peor de los casos ni si quiera ingresaron al despacho para suscribir la elaboración de la audiencia redactada por un servidor de justicia, un asistente o incluso un practicante judicial. Del mismo modo no había inmediación entre el momento de la culminación de la audiencia de pruebas y la sentencia; por lo que, los recuerdos del juez se limitaban a una nueva lectura de las actuaciones procesales lo que definitivamente quebrantaba el objetivo qué tuvo nuestra norma procesal de 1993. 
Por ello, en el presente trabajo, se buscará poner de manifiesto los problemas que podrían volver a ocurrir para la implementación de la oralidad más aún si no se ha aprendido de una historia reciente. Lo dicho aquí no tiene por objeto desacreditar o atacar la oralidad ni mostrar disconformidad con su implementación; sino por el contario de evitar vuelvan a aparecer los mismos inconvenientes que permitieron llevar a los funestos cambios que partieron del Decreto Legislativo 1071 del 26 de junio del 2008.

Consideramos que resulta necesario el cambio el cual ha de ser beneficioso; sin embargo, hay que poner de relieve algunas desventajas que se debe evitar o aminorarlas al momento de la implementación de la oralidad en nuestro sistema procesal civil

\section{Antecedentes de la oralidad}

Conforme explica Jordi Nieva en este punto, los procesos romanos se caracterizaban por ser completamente orales sin embargo no fue sino hasta la instauración de la appellatio que se hizo necesaria la protocolización de los procesos judiciales. Ello con la finalidad de que quedara plenamente documentado las actuaciones que debían ser conocidas por parte de otro ente revisar y no sea objeto de negación por alguna de las partes. (Nieva, 2020 p. 239)

Posteriormente en derecho canónico la idea de la constatación de las actuaciones y por ende su documentalización se puso de mayor manifiesto a través de la Bula Papal de Inocencio III en 1215 con la célebre frase quod non es in actis non est in mundo lo que no está en el expediente no está en el mundo. Dándole relevancia al sistema escritural, manifiesto que fue replicado no solo por la doctrina de ese entonces sino también en las decisiones judiciales acaecida. Es a continuación en la Francia del siglo XIX con el Código de Napoleón que se vuelve la mirada a la oralidad, manifestándose ello a través del Code de procédure civile de 1806 y el Code d'instruction criminelle de 1808.

Alemania recepciona este aporte napoleónico y lo plasma sobre todo en la Prozeßordnung de Hannover de 1850, así como en la actual ZPO de 1877. Austria no fue ajena a esta forma de ver el proceso lo que se vio reflejado en las ideas de Franz KLEIN, quien plasmo ese interés en su ZPO austríaca de 1895.

Al respecto Mauro Capeletti señala que históricamente además de los procesos primitivos, como el germánico, solo se estableció legislativamente la oralidad como un lineamiento exclusivo de todo procedimiento en algunos ordenamientos, como el Código Procesal Civil de Hanover de 1850, que llevó al extremo la oralidad, y fue, además, el inspirador de la Ordenanza Procesal alemana (Ziwilprozessordnung) de 1879, que inicio la tendencia hacia la oralidad en ese país, ya que en el segundo código se adoptó, en su redacción original, también una concepción más rígida y dogmática de la oralidad. (Capeletti, 1972 pp. 47-48)

España también recogió estos aportes a la oralidad, en menor medida, en Ley de Enjuiciamiento Civil de 1881 y algunas de sus reformas posteriores.

Es casualmente a partir de la aplicación práctica de la oralidad en Alemania y Austria y sobre todo por los índices favorables de duración de los procesos que Chiovenda le pone el interés en este sistema elaborado su desarrollo teórico a favor de la misma, encontrándose muy atraído por sus fundamentos teóricos. 


\section{Detrimentos al sistema de oralidad}

Vinculado al principio de oralidad. Se ha señalado que no existe un sistema propia y exclusivamente oral. Son varios los elementos a los que hace referencia Jordi con relación a ello, así precisa que resultaría ilusorio creer que un juez pueda desarrollar un proceso judicial tal como se ve en las películas; es decir que únicamente tenga un proceso sino por el contario una multitud de los mismos. Del mismo modo el principio de inmediación procesal y la presencia personal del juez en las audiencias no determina necesariamente la materialización de este principio ya que muchas veces se llevaban a cabo supuestas audiencias en las que eran solo una formalidad.

Respecto del principio de publicidad. Muchas veces los litigantes no entienden la razón por la cual existe la posibilidad de que cualquier ciudadano pueda, sin tener interés alguno en el proceso de manera directa o indirecta, estar presente en las actuaciones procesales.

Resulta poco aceptable que terceros puedan tener conocimiento de lo que les pueda pasar a quienes participan de un proceso judicial siendo intrascendente de que su problema tenga que ser ventilado ante quienes no tendrían interés alguno en lo que suceda en su caso. Sin embargo, no se analiza o se piensa en la trascendencia o importancia de este principio en cuanto a su finalidad: la búsqueda de una mayor transparencia por parte de los órganos jurisdiccionales.

Intervención de los abogados. Resulta importante que los abogados puedan estar debidamente involucrados con el sistema, el cual nace desde el momento previo a la elaboración de la demanda, saber estructurar una teoría del caso y sobre todo plantearla así ante el juez, evitando la lectura empedernida de los actuados y debiendo demostrar encontrarse involucrado en el caso. Igualmente la falta de interés en lograr culminar el proceso en la fase de conciliación, aun cuando el análisis del costo beneficio sea en perjuicio para su cliente, no existe por parte de los letrados una predisposición a conciliar sino por el contrario pretenden continuar la secuela del proceso hasta obtener una sentencia que luego será apelada, en caso le sea desfavorable, aun cuando sabe que el caso no podrá ser ganado.

Del mismo modo se advierte la falta de colaboración en la fijación de los puntos controvertidos, al no haber estudiado el caso y hacer una somera lectura del escrito de la contraparte, muchas veces prefieren reservarse esta facultad y dejar en manos del juez para que sea el quien las fije, esperando algún error para acogerse de él al momento de la apelación.

Otro aspecto a destacar es que muchos letrados participan de las actuaciones con poco conocimiento del proceso y de sus instituciones para poder reaccionar debidamente en el ejercicio de su derecho de defensa y patrocinio de la causa. Lamentablemente la poca experiencia o desinterés por este nuevo sistema conlleva a generar un perjuicio para el proceso o para las partes a las que asisten.

La costumbre de esperar acudir a sus oficinas para redactar sendos escritos argumentativos sin poder susténtalos en las actuaciones correspondientes, advirtiéndose la poca preparación en el saneamiento del proceso, más aun cuando se ha formulado excepciones o defensas previas que no la saben formular o no las saben atacar. Igualmente ello conlleva a no encantarase en la capacidad de formular los alegatos de clausura luego de la actuación probatoria con la esperanza de formular por escrito sus informes finales, lo que ya no podrá realizarse. Entonces el poco aporte que pueden brindar algunos abogados al desarrollo del proceso en razón de no estar verdaderamente empapados del caso constituye un grave problema que afecta al sistema y sobre todo a una de las 
partes que no va obtener la justicia que busca al no contar con un abogado debidamente capacitado para plantear y llevar un proceso civil bajo este sistema.

Preparación del Juez. Uno de los problemas muy comunes, que felizmente no resulta ser una generalidad, es la falta de preparación del Juez; sucede que lamentablemente en primer lugar el juez no califica la demanda ni la contestación, delegando esta función en un auxiliar jurisdiccional o un practicante en razón de "no ser un acto complejo" sino una mera evaluación formal de los requisitos de la misma. De tal forma que, está a la espera de la Audiencia Preliminar para recién tomar conocimiento de los actuados procesales y de la litis.

Asimismo, en muchos casos, no cuenta desde el inicio con un proceder que le permita proponer formula conciliatoria alguna al no conocer el caso ni haberlo analizado previamente. El siguiente correlato es la nula capacidad para señalar los puntos controvertidos del proceso, al no haber leído el caso y al limitarse al actuar de los abogados que poco o nada le han podido aportar al esclarecimiento de los hechos del caso es poco probable que pueda fijar correctamente los límites de la litis.

Cabe señalar aquí que, la falta de preparación lleva a muchas veces no resolver en el acto las excepciones o defensas previas u alguna otra actuación en la que requiera una decisión inmediata: Del mismo modo no saber dirigir ni actuar una audiencia de pruebas limitándose a ser un mero espectador de lo que los abogados desarrollan en el proceso. Y en muchos casos el temor por resolver una vez llevada a cabo las actuaciones probatorias dilatando el proceso y no resolviendo en dicho acto, permitiendo así una dilación innecesaria del proceso.

Podría decirse que el ordenamiento de origen romanista no existe esa tradición:

Por ello ha sido necesario establecer instrumentos para la preparación de la abogacía y de la judicatura, no solo en los juicios por audiencias, sino a las nuevas funciones que tiene que realizar ambas en la época actual, y para ello se han establecido escuelas judiciales o institutos de especialización judicial, así como cursos de posgrado en las escuelas y facultades de derecho para preparar a los egresados de la licenciatura en las modernas actividades profesionales. (Fix-Zamudio, 2007 p.363)

La ausencia de capacitación de los magistrados no solamente debe imputársele a ellos, toda vez que le compete al Estado brindar todas las facilidades para dotar a los magistrados de las herramientas jurídicas pertinentes que les permitan entender y comprender este nuevo sistema, así como la extensión a los demás servidores de justicia que son los colaboradores del juez. Ello sumado al cambio de mentalidad para querer llevar a cabo esta reforma del proceso civil bajo el sistema de oralidad. Pero sobre todo que estos cursos brindados por el Estado no le generen un costo al juez, que las instituciones encargadas de ello lo ofrezcan sin que los afecte patrimonialmente para poder exigirle también una mejor labor judicial.

Lo puesto en manifiesto aquí no implica que todos los jueces trabajen así, existe en el Poder Judicial un grupo de magistrados que han puesto el hombro y la predisposición así como pleno interés en lograr una transformación del sistema de justicia y están convencidos de que la oralidad debe y tiene que funcionar. Mas lamentablemente ello no es una generalidad, recordemos que si el Código Procesal Civil no funcionó casualmente fue por la dejadez de muchos magistrados, su falta de preparación y el poco o nulo interés por desarrollarlo adecuadamente pese a las carencias y limitaciones propias del sistema de justicia. 
Con la experiencia de haber sido magistrado puedo decir que si fue posible tener un despacho al día y aplicar el código materializando los principios de oralidad conociendo el proceso, resolviendo dentro de los plazos razonables sin descuidar mi propia capacitación y la de mis colaboradores, pudiendo concluir que fue una experiencia enriquecedora que lamentablemente no motivo a mis pares en la ciudad de lquitos.

Desde aquí mis respetos a dignos magistrados de las diversas Cortes de Justicia del Perú que además de la labor judicial están realizando actividad académica con el fin de difundir no solo los beneficias de este sistema sino también su experiencia propia, no quiero citarlos aquí por el temor a dejar alguno fuera de esta mención, más felizmente muchos ya sabemos a quienes nos referimos y que son los abanderados de esta transformación que requiere la suma también de otros colegas y lograr el ansiado objetivo justicia pronta y oportuna.

Material logístico y humano. Se pensó que con la puesta en vigencia del Código Procesal de 1993 se solucionarían los problemas en la administración de justicia civil y que estos conforme los plazos y desarrollo del mismo podríamos tener una justicia más célere. Sin embargo no bastaba ello, además de la puesta en vigencia de un cuerpo normativo, se requiere la implementación de material logístico y de capacitación a los auxiliares jurisdiccionales para una correcta aplicación de la ley.

A la fecha no ha cambiado en mucho esta situación el presupuesto para el Poder Judicial no ha sido objeto de mejoras y se ha hecho realmente muy poco por llegar a todo el Perú en cuanto a infraestructura y recurso tecnológicos. Para lograr la implementación de la oralidad se debe aprender de esta nefasta experiencia y mejorar o implementar sistemas más actualizados que permitan lograr los objetivos que se pretenden.

La cantidad de magistrados y personal jurisdiccional no se da abasto para reducir la carga procesal existente así como la casi nula o poca capacitación a los operadores de justicia que auxilian la labor del juez, sumado a ello, la falta de personal, los cambios repentinos de estos, personal especialista en otras áreas o personal no calificado son algunas de las situaciones de desventaja que deben ser solucionadas si se quiere tener una respuesta eficaz a la implementación de la oralidad en el proceso civil.

Igualmente, la implementación de la oralidad no ha significado la creación de nuevos órganos de justicia sino simplemente su transformación repartiendo la carga procesal de estos juzgados a los demás aumentando de esta manera el número de procesos en los despachos no implementados en oralidad, ocasionando un grave perjuicio para abogados y litigantes. Si bien es importante que los jueces de oralidad inicien con carga cero para dedicarse únicamente a los procesos nuevos bajo este esquema, sin embrago no se ha pensado en el daño causado a las partes procesales de aquellos procesos que han sido trasladados a otros despachos.

Calamandrei citado por Fix Zamudio señaló con tristeza que la oralidad había fracasado en el proceso civil italiano debido a la desconfianza entre abogados y los jueces instructores y el exceso de trabajo de estos últimos, pueden si bien celebrar reuniones puramente formales en las cuales el juez de instrucción y los abogados ocupan tres sillas ante el mismo escritorio, acompañados por el secretario, dispuesto a consignar sus palabras en el acta, por lo que podrían aprovechar el encuentro para discutir cuestiones de fondo de la controversia, pero se detiene solo unos momentos para ponerse de acuerdo sobre la fecha de la otra audiencia aparente para comunicarse por medio de escritos. (Calamandrei, s.f como se citó en Fix-Zamudio, 2007) 
Se debe evitar la mala costumbre de la trascripción de las audiencias, aun muchos jueces creen que todo debe estar documentado en formato papel, y ello sigue siendo un gran error, el código de 1993, un código de oralidad no fue entendido así; y los rezagos de la escritureidad se manifestaban en este tipo de actuaciones procesales. Se debe tener en cuenta también que en dicha época no se contaba con soportes tecnológicos que puedan almacenar de gran cantidad de información como en la actualidad (teléfonos de última generación) que pueden grabar horas de horas de actuaciones judiciales sea en audio y/o video. Nuestras clásicas grabadoras de cassett no eran utilizadas y era muy costoso ello, así como tampoco se la pensó como una alternativa para registrar las diligencias y evitar el formato papel.

Estos constituyen a mi criterio algunos rasgos vigentes de la escritureidad en el proceso civil que deben ser atacados si se quiere realmente que la oralidad cumpla con sus objetivos, ya no estamos para jueces mártires a los que se les exija ir a la guerra sin que tengan las armas para combatir a este sistema actual y les permite variar la imagen que se tiene del Poder Judicial y de sus servidores. Es un conjunto de políticas de Estado e inversión necesaria porque el solo cambio normativo o la implementación de un sistema sin ese respaldo poco pueden hacer para lograr los objetivos propuestos.

\section{Aspectos positivos del sistema escritural}

No todo es malo ni negativo en la escritureidad del proceso definitivamente hay aspectos que deberían ser puestos de manifiesto y que correspondería también sean tomados en cuenta a fin de ser mantenidos.

La escritura contribuye a centrar y fijar con bastante claridad el objeto del juicio, haciendo bueno el antiguo brocardo "scripta manent". Pero no sólo eso, sino que los escritos permiten que un letrado exprese mucho mejor su defensa, porque tiene mucho más tiempo para reflexionar. (Rosenberg, s.f. como se citó en Nieva, 2020).

Otro aspecto a que hace referencia es el relativo a que mediante la escritureidad, se podrían simplificar algunos trámites en atención de no contar con audiencias para casos que podrían ser resueltos única y exclusivamente basados en el material probatorio existente y sin necesidad de actuación alguna, podríamos pensar en determinados procesos no contenciosos que no requieran de diligencia alguna y pueda ser resulta por el juez en su despacho.

La escritura en el proceso, permite de alguna forma un mayor tiempo para análisis así como para poder documentarse doctrinaria, legal y jurídicamente; ya que no solamente se va a sustentar en los conocimientos previos sino que también va a organizar de mejor forma el marco teórico de su teoría del caso principalmente al momento de los alegatos finales. Información que puede resultar de relevancia para el juez en el proceso y pueda contar con todos esos elementos y poder resolver con mayor sustento además del aspecto factico y probatorio del caso.

\section{Principios que sustentan la oralidad}

Se ha señalado que el sistema de oralidad se sustenta en tres principios básicos que son propiamente la consecuencia de esta nueva forma de ver el derecho civil.

Inmediación. Precisa que la inmediación sólo implica que el Juez tiene percepción directa de las actuaciones procesales, sin intermediarios, especialmente, por lógica, de las actuaciones probatorias (Nieva, 2020 p. 250). También decimos que: 
"la inmediación se quiere significar que el juez o tribunal está presente en las audiencias públicas en unión de las partes para realizar la fase oral del proceso, por lo que a criterio de este autor, la inmediación debe considerarse como el aspecto básico de la oralidad." (FixZamudio, 2007 p. 358)

Ello implica el contacto visual y no necesariamente personal del juez con las partes y los medios probatorios que va a actuar. Y señalamos que no es requiere ser estrictamente personal en razón de que en los tiempos actuales (COVID-19) será poco probable que las partes acudan a los despachos judiciales para poder llevarse a cabo las actuaciones procesales en las que se requiera la presencia física de los mismos; por ello los diversos sistemas informáticos de comunicación serán muy importantes en el proceso oral sobre todo estableciendo protocolos para la ubicación de los equipos que permita por parte del juez la visualización de los sujetos intervinientes y se pueda evitar algún tipo de intervención inadecuada de los abogados y al mismo observar el comportamiento de los mismos en el desarrollo de las diligencias.

Fix-Zamudio estima que la identidad física del juzgador implica que el juez o los miembros del tribunal que recibieron oralmente los argumentos, alegatos y los elementos de convicción de las partes son las mismas personas que deben dictar la resolución definitiva, pus en principio, cuando se trata de una situación del juzgador, si el que dicta el fallo no estuvo presente en las audiencias probatorias carece, en principio, de los elementos suficientes para resolver con eficacia la controversia. (Fix-Zamudio, 2007 p. 358-359)

Lo que se busca es que sea el juez que va a emitir la sentencia sea quien ha participado durante toda la secuela del proceso y que haya intervenido en las actuaciones procesales lo que le permite un conocimiento directo e inmediato de la secuencia litigiosa. De allí que va a poder percibir cada una de las diligencias en las que las partes o terceros tengan que declarar ante él, por lo que no ha de limitarse a la lectura de la transcripción de las actuaciones sino al contacto que le permita valorar e identificar las diversas reacciones de estos.

Concentración. Para Fix Zamudio significa en esencia, que el procedimiento no debe fragmentase en diversas etapas preclusivas, lejanas en el tiempo unas de otras y con constantes impugnaciones de numerosos actos procesales intermedios, como ocurre con el proceso predominante o exclusivamente escrito, el que se prolonga excesivamente en el tiempo, y eso sin tomar en cuenta los que el gran procesales español Nieto Alcalá Zamora y castillo califica como entreactos procesales, es decir, los periodos en los cuales se presenta la actividad de las partes y del juez, que rebasan notoriamente los plazos y términos de los códigos. (Fix-Zamudio, 2007 p. 358)

Implica la realización de varias actuaciones judiciales en el menos número posible de las mismas. Lo que se busca es la unicidad o agrupación a fin de que las dilaciones puedan o generen un perjuicio para la secuencia propia del proceso y para las partes procesales.

Lo que el juez debe evitar es que las actuaciones, no solamente sean largas tediosas e innecesarias, sino también que se prolonguen en el tiempo y que se señalen nuevas fechas para su continuación que sean tan distantes y generen perdida de la unicidad en la actuación judicial. Los que implica leer las sesiones anteriores para recordar lo actuado y continuar en el momento en que estas se realizaron, por ello la importancia de la grabación de las actuaciones y su correcto registro y almacenamiento para evitar esta circunstancia. 
Publicidad. se precisa que por oralidad debe entenderse aquella fase del procedimiento en la que están y participan activamente el juez o el tribunal como las partes y las personas interesadas, pero además cuando los actos del procedimiento pueden ser observados directa y públicamente por el público en general, así como, con algunas limitaciones, por los medios de comunicación (FixZamudio, 2007)

Un aspecto que dista de ser un comentario favorable a este principio lo señala Jordi para quien aunque en la actualidad dicho principio siga teniendo su debido peso, debe tenerse presente, como indiqué al inicio, que las partes que acuden a una vista judicial no entienden mucho de lo que allí sucede, por lo que la garantía de la publicidad acaba convirtiéndose en algo completamente inefectivo, en una farsa en definitiva. No ya por el lenguaje jurídico, sino porque el contenido de las vistas tiene una importante parte que alguien que no sea jurista no va a entender, exactamente igual que le ocurre a cualquiera que no sea médico cuando observa la realización de una intervención quirúrgica. (Nieva, 2020, pág. 252)

Existe poco o nulo interés por el ciudadano de a pie participar efectivamente en las audiencias públicas, salvo que tengan algún interés o por la trascendencia del caso amerite estar presente. Si bien se piensa que con este principio se busca fiscalizar de alguna manera la actuación judicial y se pueda evitar actos de arbitrariedad, ello en buena cuenta no es del todo cierto ya que no necesariamente existe algún tipo de presión, como si lo ejercen los medios de comunicación respecto de lo que un juez va a decidir en un proceso.

Otro aspecto de esta publicidad está dada por la posibilidad de acceso a las actuaciones procesales mediante los sistemas de internet, encontrándose toda la información en las páginas web de los entes judiciales o algunas entidades especializadas que ponen de manifiesto algún proceso judicial que por su trascendencia corresponda hacerlo de acceso público.

Aquí, es importante desatacar la existencia del expediente virtual, por el cual sobre todo las partes tienen acceso inmediato a las actuaciones judiciales y no requieren de acudir a las salas de lectura o al despacho del juez para tomar conocimiento de lo que se viene desarrollando en el proceso.

Este principio, muy vinculado a la oralidad permite que las actuaciones judiciales puedan ser vistas en vivo a través de los canales de televisión o de algunas plataformas virtuales en las que uno pueda tener acceso en vivo a lo que ocurre o en todo caso poder visualizar con posterioridad si esta ya es colgada en las páginas correspondientes y poder verificarlas en el momento que considere pertinente.

Más allá del aspecto hasta aquí mencionado, corresponde traer a colación lo precisado por Jordi quien, concluye que, lo único que deseaba evidenciar es que no parece conveniente hablar de principios consecuencia de la oralidad o de la escritura, en las condiciones actuales. Y que por ello, quizás sea oportuno empezar a estudiar esta materia de los principios del procedimiento prescindiendo que el origen de todo sea la oralidad o la escritura, porque ello otorga una imagen teórica que no se compagina con la realidad de las cosas. (Nieva, 2020, p. 254)

\section{Oralidad, escritureidad o playdoh procesal}

Hasta ahora, se puede señalar que sería o es poco probable optar por un sistema exclusivamente oral o únicamente escritural, cada uno tiene ventajas y bondades que deben ser aprovechadas en 
bien del sistema de justicia y sobre todo en beneficio de los litigantes que sufren diariamente las desventuras de un Estado que no ha sabido dar respuesta al deseo de una justicia oportuna y eficaz.

Al respecto Mauro Capeletti al referirse a la oralidad puso de manifiesto que este sistema tiene sus límites, y constituye una ilusión considerar que pude establecerse sin apoyo de documentación escrita, pues eliminar esta última, seria caer en el otro extremo de considerar que la oralidad es un principio absoluto y exclusivo, ya que, por el contrario, ésta y la escritura deben convivir en el proceso moderno en proporción adecuada. Por tanto, lo que debe establecerse es la relación más favorable de coexistencia entre la forma oral de los actos procesales y la forma escrita de los mismos. (Capelleti, 1972 pp. 85-87)

Por ello resulta armar con ambas un sistema en la que puedan de acuerdo a sus características estar presentes en las fases del proceso en las que su intervención sea la más beneficiosa, amalgamándolas para poder armar un nuevo sistema más acorde a nuestra realidad y necesidad.

Goldschmidt, quien considera que el principio de oralidad significa que solamente las alegaciones expresadas oralmente pueden llegar a constituir fundamentos del fallo. (Goldschmidt, 1936 p. 86) De tal manera que no existe sistema procesal en que sea completamente oral, porque si no se dejarían de lado otras actuaciones que requieren estar plasmadas en actos escritos.

Por su parte, Giuseppe Chiovenda considera que la escritura debe desempeñar concretamente dos papeles en un proceso oral: servir como preparación para el tratamiento del proceso y servir como documentación de lo actuado en las audiencias. (Chiovenda, s.f., pp.132-133)

Así, sabido es que nuestro proceso judicial transcurre por cinco etapas: a) postulatoria; b) probatoria; c) decisoria; d) impugnatoria y e) ejecutoria. Cada una de estas faces de acuerdo con las características propias podría dar la prioridad a uno u a otro sistema que mejor pueda encajar y por ende dar mayor prevalencia a la oralidad o a la escritura, brevemente las mencionaremos aquí.

\section{Etapa postulatoria}

En un primer momento es propiamente escritural la demanda, su calificación, la contestación, las excepciones, las defensas previas, las cuestiones probatorias, son actos procesales que se formalizan mediante documentos, allí vemos la prevalencia de este sistema y que no podría ser de otra forma dada la necesidad de encontrarse debidamente acreditados estos hechos en formato papel.

Respecto a este aspecto resulta importante la aplicación de este sistema por su trascendencia en la evolución del ser humano, por ello Juan Monroy señala que "(...) hasta el momento el medio más idóneo que el intelecto humano ha creado para perpetuar y acreditar la ocurrencia de un hecho o la manifestación de una voluntad." (Monroy, 2009, p.199)

En un segundo momento en la Audiencia Preliminar se advierte la manifestación de la oralidad ya que en las diversas actuaciones no habrá mayor actuación escrita así, desde los alegatos de apertura, la propuesta de conciliación, el saneamiento procesal, la fijación de puntos controvertidos y hechos no controvertidos, así como el saneamiento probatorio, se han de llevar de manera oral. 


\section{Etapa probatoria}

Esta fase es llevada propiamente de manera oral, que implica la actuación de los medios probatorios, como la declaración de parte, la declaración de testigos, los documentos, la pericia, la inspección judicial y el alegato de clausura se han de desarrollar bajo el sistema de oralidad, sin perjuicio del soporte del mismo que conforme señala Jorge Peyrano,

Hoy, en cambio, el camino preferido es el de la documentación audiovisual de lo sucedido en las audiencias probatorias, pues así se dota al magistrado de la chance de observar y no sólo de oír lo acontecido. (...) Obviamente el actuario participante debe, en el caso de la filmación de audiencias probatorias, formalizar una breve acta, dando cuenta de que en tal día y en tales actuaciones se celebró una sesión probatoria; conservando una copia de la filmación en el recinto del tribunal (...). (Peyrano, 2011 pp.167-168)

\section{Etapa decisoria}

Esta fase o etapa resulta ser un momento discrecional del juez en cuanto a su realización, toda vez que culminada la audiencia de pruebas y realizada o no el alegato de clausura por parte de los abogados, el juez puede oralmente expedir la sentencia o reservarse el derecho de hacerla esta por escrito.

En el primer caso, no impide que posteriormente sea notificada por escrito la sentencia luego de haberla oralizado en la audiencia. En el segundo supuesto, con posterioridad a la actuación judicial se ha de notificar físicamente la decisión judicial que pone fin al proceso o a la instancia, a fin de que las partes tengan conocimiento de lo resuelto por el Juez.

\section{Etapa impugnatoria}

Esta etapa se encuentra también en función a si la sentencia fue oral o escrita, por lo que en el primer caso podrá en dicho momento proceder a impugnar oralmente la sentencia, sin perjuicio de que esta deba y tenga que ser sustentada necesariamente mediante el escrito correspondiente cumpliendo los requisitos de ley para el caso de los medios impugnatorios a proponerse, sea la apelación y/o la casación.

Marianella Ledesma Narváez describe esta etapa de la manera siguiente: "La vista es la audiencia ante los colegiados, en la cual se examina una causa, se debate acerca de la misma y se deja al voto para su decisión. Es la declaración que el juez o el colegiado de haber estudiado todo un expediente".

Asimismo, respecto del informe oral, dicha autora señala que "Es la exposición oral que hacen los abogados en una etapa del proceso para reafirmar los alegatos que sirven de sustento a la pretensión del litigante que patrocinan. Por su parte, los litigantes también pueden formular oralmente alegatos sobre hechos, en la instancia respectiva y en los casos que la ley le faculte". (Ledesma, 2015, p. 174)

\section{Etapa ejecutoria}

Fase de actuación que implica la realización de actos materiales para llevarse a cabo estando que en algunos casos puede esta realizarse mediante actuaciones judiciales llevadas a cabo por el 
auxiliar de justicia o en otros casos por meros documentos entre el juez y los órganos que deben ejecutar la decisión, por lo que en ese supuesto se realizará mediante la escritura.

\section{Conclusiones}

La idea del presente trabajo no es cuestionar u oponernos al sistema de oralidad, sino mostrar las falencias existentes y las que se pudieran presentar a fin de poder de manera previa analizarlas y evitar que estén puedan ponerse de manifiesto y entorpecer su desarrollo.

Impedir que los detractores puedan utilizar tales situaciones negativas como abanderado del cuestionamiento a la oralidad queriendo impedir el cambio que se pretende.

\section{BIBLIOGRAFÍA}

- Capeletti, M. (1972). La oralidad y las pruebas en el proceso civil. Trad Sentis Melendo, Santiago. Buenos Aires: Ediciones Juridicas Europa America.

- Chiovenda, G. (s.f.). Instituciones de Derecho Procesal Civil. Gómez Orbaneja, Emilio, tr. $2^{a}$ ed. Madrid: Revista de Derecho Privado.

- Fix-Zamudio, H. (2007). Aproximación al estudio de la oralidad procesal, en especial en materia penal. En Estudios juridicos en homenaje a Cipriano Gómez Lara (págs. 347-426). Mexico: Porrua.

- Goldschmidt, J. (1936). Derecho Procesal Civil. Prieto Castro, Leonardo, tr. . Barcelona: Editorial Labor.

- Ledesma Narváez, M. L. (2015). Comentarios al Código Procesal Civil. Análisis artículo por artículo. $5^{a}$ ed. T. 2. Lima: Gaceta Jurídica.

- Monroy, J. (2009). Teoría General del Proceso. $3^{a}$ ed. . Lima: Communitas.

- Nieva, J. (16 de 05 de 2020). Problemas de la oralidad. Obtenido de http://www.bibliotecad. info/wp-content/uploads/2018/08/Los-Problemas-de-la-oralidad.pdf: http://www.bibliotecad. info/wp-content/uploads/2018/08/Los-Problemas-de-la-oralidad.pdf

- Peyrano, J. (2011). Nuevos horizontes de la oralidad y de la escritura. En sus principios procesales T 2. Buenos Aires: Rubinzal Culzoni Editores.

Fecha de recepción: 22 de mayo de 2020

Fecha de aceptación: 01 de junio de 2020 